\title{
Communication in health care teams
}

\author{
Juan B. Dartiguelongue, M.D..$^{a-c}$ and Pablo J. Cafiero, M.D. ${ }^{b, d}$
}

\begin{abstract}
An essential characteristic of health care facilities is teamwork, and this implies an organizational philosophy where collective talent, with common goals in clearly identified directions, allows to obtain better results. Communication is at the core of this model, understood as an interaction process, not just an activity aimed at conveying information. Medical errors and conflict in the institutional setting are usually caused by failures in effective communication. Like in other areas of health, communicational aspects of teamwork advance with learning. The acquisition of such competences, the development of active listening, and an interaction among disciplines favor professional training and patient safety. Actually, together with other factors, these aspects necessary for communication underscore the quality of health care.

Key words: communication, patient care group, interdisciplinary communication.
\end{abstract}

Hospital de Niños Ricardo Gutiérrez, Autonomous City of Buenos Aires, Argentina.

b. Department of Pediatrics, School of Medicine, Universidad de Buenos Aires, Argentina.

c. Sociedad Argentina de Pediatría, Metropolitan Area, Autonomous City of Buenos Aires, Argentina.

d. Hospital de Pediatría S.A.M.I.C "Prof. Dr. Juan P. Garrahan," Autonomous City of Buenos Aires, Argentina.

E-mail address:

Juan B. Dartiguelongue, M.D.:

jbdartiguelongue@ hotmail.com

Funding:

None.

Conflict of interests: None.

Received: 1-12-2021 Accepted: 6-10-2021 http: / / dx.doi.org/10.5546/aap.2021.eng.e589

To cite: Dartiguelongue JB, Cafiero PJ. Communication in health care teams. Arch Argent Pediatr 2021; 119(6):e589-e593.

\section{INTRODUCTION}

Communication is inherent to human beings. It involves two or more people exchanging messages in different ways, in a spatial and historical setting, establishing meanings and transmitting beliefs. Such phenomenon, both common and particular, shapes the possibility of understanding and, therefore, defines human relationships. ${ }^{1,2}$ Communication accounts for a mutually influential event, where each party adjusts their behavior as a response to the other person. ${ }^{3}$

It helps to build reality because it supports the development of society, art, and culture while, at the same time, establishing the basis for consensus, dissent, and empathy among people.

Even in the absence of words, communication is constant and continuous. Body positions, facial expressions, breathing, mimicking, and gestures broaden communication channels, which allow a person to make interpretations based on their mood, feelings, and nature.

Communication will be effective as long as it reinforces the understanding of the message in all of its domains. ${ }^{4}$ Not surprisingly, communication is recognized as one of the core factors for maintaining work safety and quality, especially among teams which perform complex activities. ${ }^{5}$ In the setting of health care, the effectiveness of communication plays a key role as a process based on interaction, far from being just an activity aimed at conveying information. ${ }^{6}$

The models that render communication from a perspective that weighs the relationship among human beings understand message transmission in an helical form, unlike the linear representation of the classical mechanistic model. These models are adequate to define communication in health care, where, in addition to conveying messages in a sufficiently intelligible manner, it is also important to consider who receives them for the understanding and interpretation of their meaning. ${ }^{1}$

For a long time, research in communication was based on the presence of words, what is said or not said. However, the importance of silence is evident for anyone who is or has been a member of a health care team, especially when it comes to functional or significant silence. ${ }^{7}$

The quality of health care depends directly on the functioning of work teams and, therefore, such effective professional exchange serves as the cogs and wheels in the system. ${ }^{8}$ How something is communicated is as important as the content; therefore, knowing how to communicate is 
a basic, relevant skill. In addition, these competences are a fundamental pillar in medical training and in the development of the patientdoctor relationship. These aspects of teamwork can be learned and focused on the safety and well-being of both patients and their families. ${ }^{8-10}$ In addition, the development of communication skills is a preventive factor for the development of burnout syndrome, which invariably affects the quality of care.

\section{COMMUNICATION, WORK TEAMS, AND PATIENT SAFETY}

A team is defined as two or more people with specific functions and performing interdependent tasks, who are flexible to adaptation and share a common goal. Teamwork is not simply working together; it implies an organizational philosophy regarding the leverage of collective talent. To this end, it is necessary for health care providers to have communication skills and abilities and to come from different backgrounds for the common purpose of achieving clearly identified goals. ${ }^{11,12}$

Working alone, with little and ineffective communication within and among teams in a health care facility is one of the main obstacles to providing safe and good quality health care. ${ }^{5}$ Actually, more than half of severe damage and deaths are caused by the failure in team communication with the patients and their families. ${ }^{13-15}$

In this situation, institutions should encourage a cultural change in how errors are addressed, supported in communication, whose horizon is to promote the corresponding competences among teams, patients, and their families. ${ }^{16}$

Several strategies may be implemented in order to identify and correct weaknesses and reduce errors given that certain scenarios are particularly inclined to an ineffective communication. This is the case of handoffs, consultations, wording of medical indications, and patient transfer within facilities, among others. ${ }^{17}$ The systematic assessment in these settings using checklists and simulations, among other tools, is fundamental to improve the quality of health care and, therefore, patient safety because it allows to measure the impact of errors and detect weak spots from where errors may spread. . $^{18-20}$

In addition, the development of active listening in all work occasions, the generation of conflict solving tools, and interdisciplinary work are key elements to optimize communication in the institutional setting.

\section{ACTIVE LISTENING}

Speaking is effective only if it results in the desired listening in the other person. To achieve it, listening to what the other person says is not the only requirement; it is also necessary to pay attention to what is said. This is the most evident manifestation of the ability to have an interpersonal relationship and understand the other person in their environment. Active listening implies paying attention not only to what is said, but also to what is meant to be said, what is expressed with the body and its meaning. ${ }^{21}$ It allows to understand the context and non-verbal language, perceive emotions, and improve information. In turn, it is a response to the interest in the other person's account, avoiding early assumptions or wrong signs, and fosters what is meant to be caused in the other party. ${ }^{4,21}$

Different approaches are required to achieve active listening. On the one side, not foreseeing the message of the other person (prejudice), together with facilitating the account, nodding, inviting the other person to continue, making clarifications, asking for examples, sharing thoughts, making functional silent periods, and showing empathy favor discourse and increase the ability to understand. ${ }^{3}$

Many times, the need for immediate answers, the little leveraging of linguistic and paralinguistic resources, the urgency required to make certain decisions, and the performance of simultaneous tasks hinder active listening. It is clear that, in these scenarios, the time devoted to communication is not enough ${ }^{22}$ and the lack of interest in the other person's account, probably due to stress or burnout syndrome, lead to gaps in communication, the origin of the conflict among health care providers within a facility. ${ }^{23}$

\section{CONFLICT AND NEGOTIATION}

Conflict is a typical phenomenon among human beings, often caused by failures in interpersonal communication. Usually, it has a bilateral origin and feeds on underlying phenomena, such as memories, experiences, dislikes, and prejudices, that affect the conveyance and projection of messages. ${ }^{24}$ Conflict may be influenced by desires, moods, interpretations, and expectations. Not infrequently, many opinions about other people are based on beliefs or events that have not been verified. Such assumptions progressively shape the possibility for understanding, limit interactions, and restrict an effective communication..$^{24-26}$ 
Self-image and the extent to which we know the other person may be the origin of difficulties in mutual understanding. For example, people or groups with a negative image about themselves tend to perceive certain messages as personal attacks, whereas the better someone knows a group or person, the easier it is to interpret their messages. However, communication among health care providers is commonly established with people they do not know: patients, their families, other health care providers; this should not in any way disallow dialog or limit the ability to understand and feel empathy.

Conflict resolution may result from different negotiation styles. With the competitive negotiation style, the conflict controls the scene where one party wins and the other one loses. The satisfaction of the basic interests of each party excludes the possibility of satisfying the other person's interests; this is a hard style with extreme positions. In general, it takes place in the absence of trust in the group, when the relationship and common goals are minimal, thus supporting the little interest and the distance between the parties. ${ }^{27}$

Instead, the collaborative negotiation style attempts to satisfy the basic interests of each party after a balanced process of careful analysis of attitudes and potential resolution. This means that it proposes approaching an ideal situation where both parties achieve the desired agreement. The basic interests of each party, understood as their needs, intentions, and desires -the reasons why they want or wish something- may be shared, different, or opposite. The individual or group stance is outlined based on this, thus establishing a strategy for conflict resolution. I.e., what each individual or group expresses that they want to achieve based on an account that supports the individual or group identity. Making each party's interests clear and developing new sustainable stances are critical aspects in this negotiation style. This reveals the importance of focusing on interests rather than on a stance, ${ }^{27}$ leaving professional ego aside and focusing the interest on the patients and their families.

\section{MULTIDISCIPLINARITY, INTERDISCIPLINARITY, AND TRANSDISCIPLINARITY}

The pluridisciplinary nature of health care, characterized by the intervention of different teams of health care providers, entails a collaborative working methodology that attempts to improve the level of care. In this setting, it is critical to include the messages of the different specialists and providers from other disciplines who are sometimes involved in providing care from a partial, more focused perspective. ${ }^{3}$

For patients and their families, experiencing a disease includes their perspective and way of understanding what is happening, the meaning assigned to it, their culture, and their context. Likewise, health care providers and the team to which they belong are also framed in a personal context, with their own characteristics and knowledge. Interprofessional relationships include several opinions, perspectives, and future instructions in the communication process among disciplines.

A discipline may be defined as the organizational categorization of empiric knowledge, which divides and specializes the knowledge that serves as the basis for science. It tends to be autonomous and restricts the boundaries dividing it. It uses its own language and techniques and may originate its own theory.

In the interaction among disciplines, it is worth noting the different modalities, including multidisciplinarity, interdisciplinarity, and transdisciplinarity. ${ }^{28}$ Multidisciplinarity is the management of several disciplines regarding a common phenomenon that encompasses or affects them, but separately. For example, in a multidisciplinary investigation, the experts from each discipline work on the topic focusing only on their field of study, without taking into account the work of the rest. In the end, it is a collection of each discipline's perspective about a specific topic. For example, child maltreatment may be studied from the point of view of law, sociology, psychology, medicine or even history. Multidisciplinarity implies the thematic fusion of disciplines that function separately to treat a common problem. ${ }^{28-30}$

Instead, interdisciplinarity is characterized by the existence of a reciprocal relationship among disciplines, which try to identify and solve the same problem. ${ }^{28}$ It refers to revealing something that lies in the common border of several disciplines. It uses one's methods and transfers them to the other, in an exchange of theoretical and practical knowledge. It is a model of cooperation that establishes a dialog for their interaction and finds a point in common to support their work. ${ }^{31,32}$ There are three types of interdisciplinarity: ${ }^{28}$ 
- Interdisciplinarity as an application; e.g., imaging methods applied to medical diagnosis.

- Interdisciplinarity as epistemology; e.g., the methods of formal logic transferred to epistemology and research methodology.

- Interdisciplinarity as the origin of new disciplines; e.g., the transfer of methods from chemistry and physics, which enables the development of pharmacology.

On its side, transdisciplinarity is defined as the process of building knowledge through several theoretical and empirical works, open to diversifying trends inseparable from reality. It refers to basis or explanation of the disciplines from which common grounds are built. This approach is conceived as a superior emerging knowledge, resulting from a dialectical movement of thought, which allows crossing the borders of different areas of discipline knowledge and creating more complete and comprehensive images of reality. ${ }^{28}$ In the presence of such direction taken by the complexity of human beings, health and disease processes are addressed from the perspective of multicausal networks, where there is room for all kinds of knowledge established, ${ }^{33}$ including epidemiology, physiology, pharmacology, social medicine, psychology, anthropology, and neuroscience, among others.

\section{CONCLUSION}

Teamwork is the mainstay of health care facilities. For care to be safe, empathetic, and of good quality, it is critical to encourage the development of communication skills. Such commitment ensures the dialog and interaction among health care providers and disciplines, and the result will invariably have an impact on the patients' and their families' well-being.

\section{REFERENCES}

1. Ruiz Moral R. Comunicación clínica: principios y habilidades para la práctica. Madrid: Panamericana; 2014.

2. Clèries X. La esencia de la comunicación en educación médica. Educ Med. 2010; v13(1):25-31.

3. RodríguezS, Vassallo Juan C. Comunicación en la atención médica. In: Sociedad Argentina de Pediatría. PRONAP. 2016; 2(1):45-74.

4. Klein ER. Effective communication with patients. Pa Nurse. 2005; 60(4):14-5.

5. Ceriani Cernadas JM. La comunicación en los equipos de atención médica: un desafío esencial para mejorar la seguridad del paciente. Arch Argent Pediatr. 2014; 112(2):114-5.

6. Becker C,HunzikerS. Die Wichtigkeit der Kommunikation in der Arzt-Patienten-Beziehung. Ther Umsch. 2019;
76(5):231-8.

7. Lingard L. Productive complications: emergent ideas in team communication and patient safety. Healthc Q. 2012; 15(Spec No):18-23.

8. Lee CT, Doran DM. The Role of Interpersonal Relations in Healthcare Team Communication and Patient Safety: A Proposed Model of Interpersonal Process in Teamwork. Can J Nurs Res. 2017; 49(2):75-93.

9. Deveugele M. Communication training: Skills and beyond. Patient Educ Couns. 2015; 98(10):1287-91.

10. Lifchez SD, Cooney CM, Redett RJ $3^{\text {rd }}$. The Standardized Professional Encounter: A New Model to Assess Professionalism and Communication Skills. J Grad Med Educ. 2015; 7(2):230-3.

11. Ruberton PM, Huynh HP, Miller TA, Kruse E, et al. The relationship between physician humility, physician-patient communication, and patient health. Patient Educ Couns. 2016; 99(7):1138-45.

12. Coomber P, Clavarino A, Ballard E, Luetsch K. Doctorpharmacist communication in hospitals: strategies, perceptions, limitations and opportunities. Int J Clin Pharm. 2018; 40(2):464-73.

13. Topcu I, Turkmen AS, Sahiner NC, Savaser S, Sen H. Physicians' and nurses' medical errors associated with communication failures. J PakMed Assoc. 2017; 67(4):600-4.

14. Bittner-FaganH, Davis J, Savoy M.Improving PatientSafety: Improving Communication. FP Essent. 2017; 463:27-33.

15. Khajouei R, Abbasi R, Mirzaee M. Errors and causes of communication failures from hospital information systems to electronic health record: A record-review study. Int J Med Inform. 2018; 119:47-53.

16. Bascuñán ML, Arriagada AM. Comunicación de errores médicos a pacientes y familiares: interrogantes y herramientas. Rev Med Chil. 2016; 144(9):1185-90.

17. Ahmadipour $\mathrm{H}$, Nahid M. Medical error and related factors during internship and residency. Indian J Med Ethics. 2015; 12(4):215-9.

18. Fischhoff B. Evaluating science communication. Proc Natl Acad Sci U S A. 2019; 116(16):7670-5.

19. Kalet A, Pugnaire MP, Cole-Kelly K, Janicik R, et al. Teaching communication in clinical clerkships: models from the macy initiative in health communications. Acad Med. 2004; 79(6):511-20.

20. Ruiz-Moral R, Pérula de Torres LA. Validez y fiabilidad de un instrumento para evaluar la comunicación clínica en las consultas: el cuestionario CICAA. Aten Primaria. 2006; 37(6):320-4

21. Kacperek L. Non-verbal communication: the importance of listening. Br J Nurs. 1997; 6(5):275-9.

22. Blackburn J, Ousey K, Goodwin E. Information and communication in the emergency department. Int Emerg Nurs. 2019; 42:30-5.

23. Brahams D, Zeitlin H. Communication between doctors and lawyers. Med Leg J. 2018; 86(2):61-2.

24. Littlejohn S, Domenici K. Engaging communication in conflict: Systemic Practice. London: SAGE Publications, Inc; 2000.

25. González-Romá V, Hernández A. Climate uniformity: its influence on team communication quality, task conflict, and team performance. J Appl Psychol. 2014; 99(6):1042-58.

26. Jameson JK. Transcending intractable conflict in health care: an exploratory study of communication and conflict management among anesthesia providers.J Health Commun. 2003; 8(6):563-81.

27. Ingouville F. Negociación Creativa, objetivos, obstáculos y soluciones. Rev La Trama. 2004;10.

28. Choi BC, Pak AW. Multidisciplinarity, interdisciplinarity and transdisciplinarity in health research, services, education 
and policy: 1. Definitions, objectives, and evidence of effectiveness. Clin Invest Med. 2006; 29(6):351-64.

29. Gronenborn AM. Integrated multidisciplinarity in the natural sciences. J Biol Chem. 2019; 294(48):18162-7.

30. Sluiter JK, Bos AP, Tol D, Calff M, et al. Is staff well-being and communication enhanced by multidisciplinary work shift evaluations? Intensive Care Med. 2005; 31(10):1409-14.

31. Lancaster G, Kolakowsky-Hayner S, Kovacich J, GreerWilliams N. Interdisciplinary communication and collaboration among physicians, nurses, and unlicensed assistive personnel. J Nurs Scholarsh. 2015; 47(3):275-84.

32. Fathi R, Sheehan OC, Garrigues SK, Saliba D, et al. Development of an Interdisciplinary Team Communication Framework and Quality Metrics for Home-Based Medical Care Practices. J Am Med Dir Assoc. 2016; 17(8):725-9.e10.

33. Vyt A. Interprofessional and transdisciplinary teamwork in health care. Diabetes Metab Res Rev. 2008; 24 (Suppl 1):S106-9. 